\title{
Standard biliary stenting technique
}

\author{
RICHARD A KOZAREK, MD
}

RA KOZAREK. Standard biliary stenting technique. Can J Gastroenterol 1993; $7(6): 477-481$. Placement of standard polyethylene prostheses into the biliary tree presupposes use of a therapeutic endoscope in most instances, as well as access to a full range of accessory equipment to include sphincterotomes, guidewires, dilating and balloon catheters, and stents of variable length and diameter. Paradoxically, most patients with malignant stenoses can be stented without sphincterotomy, whereas the latter usually is required in a patient with benign stricture in whom multiple interventions are inevitable. Placement caveats include proper scope positioning, dilation of tight stenoses, assurance of adequate guidewire above the stricture, use of stiffening catheters and assurance of subsequent biliary decompression postprosthesis insertion.

Key Words: Bile duct, Cancer, Endoprosthesis, Fistula, Injury, Pancreas, Stent, Stricture

\section{Technique d'endoprothèse standard}

RÉSUMÉ: La pose de prothèses de polyéthylène standard dans l'arbre biliaire suppose le recours à l'endoscopie thérapeutique dans la plupart des cas, de même qu'un accès à une gamme complète d'instruments, notamment de sphinctérotomes, des guides, des cathéters de dilatation munis de ballonnets et de prothèses de longueur et de diamètres divers. Paradoxalement, la plupart des patients atteints de sténoses malignes peuvent être traités par une endoprothèse sans sphinctérotomie, alors que cette dernière est habituellement nécessaire chez le patient atteint d'un rétrécissement bénin qui aura besoin de multiples interventions. Les précautions à prendre concernent le positionnement adéquat à l'aide de la scopie,la dilatation des sténoses serrées, la présence d'un guide adéquat au-dessus de la stricture, le recours à des cathéters de redressement et l'assurance d'une décompression après l'insertion de la prothèse.

$\mathrm{B}$ ILIARY ENDOPROSTHESES, ORIGI. nally used for malignant obstructive jaundice caused by primary pancreatic and biliary malignancies and porta hepatis metastases (1-9), increasingly have been used for benign disease. Indications for the latter include benign biliary stenoses (postoperative, sclerosing cholangitis, chronic pan- creatitis), biliary fistulas, and unretrievable biliary calculi in high risk patients (10-21).

\section{TECHNIQUE}

Standard stenting techniques are presented in Figures 1 to 4 . The endoscopic approach to biliary endoprosthesis placement is dependent upon both the clinical situation (urgency, benign versus malignant disease) and equipment availability. In the patient with an ill-defined biliary stenosis, for instance, evaluation with abdominal computed tomography scan, carcinoembryonic antigen or CA 19-9 tumour markers, or directed brushings or biopsies may be required prior to or concomitant with endotherapy. From the equipment standpoint, endoprosthesis placement requires access not only to $4.2 \mathrm{~mm}$ channel, therapeutic duodenoscopes, but also a full range of accessory equipment. The latter include, but are not limited to, $0.018 "$ 0.052 " guidewires, nitinol, torqueable wires, glide wires, sphincterotomes, dilating catheters and balloons, and prostheses of various length, diameter and configuration.

From a technical standpoint, a good quality endoscopic retrograde cholangiopancreatography is a prerequisite for stent placement. Paradoxically, while sphincterotomy is not required for many cases of malignant disease, it should be considered in most cases of benign disease in which multiple therapeutic manoeuvres are anticipated over one to two years. In either setting, endoscopic sphincter section facilitates passage of accessory equipment, such as dilating balloons, and allows placement of multiple or large diameter endoprostheses. Antibiotic coverage, unlike sphincterotomy, is an absolute prerequisite when dealing with an obstructed or leaking biliary tree or a contaminated bile duct in which a stent has been previously placed. 


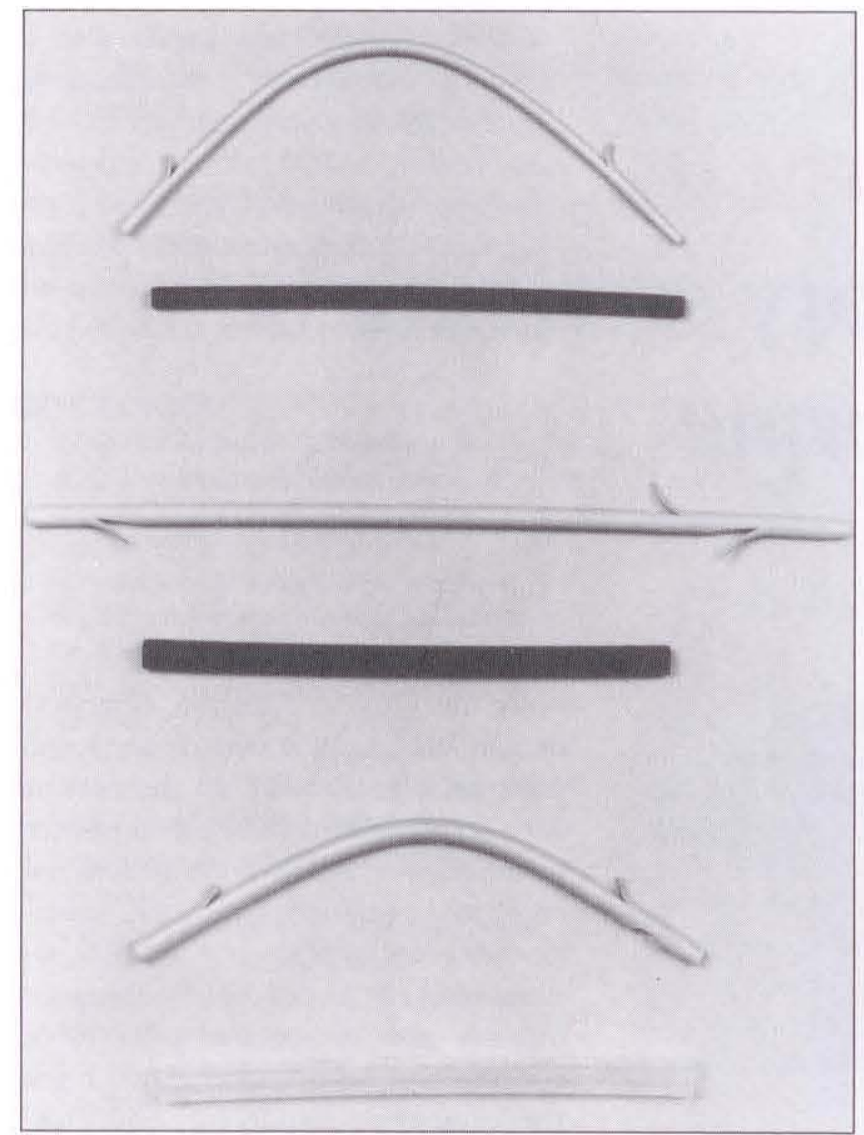

Figure 1) 7 (top), 10 (middle) and 11.5 (bottom) French Amsterdam-type biliary prostheses

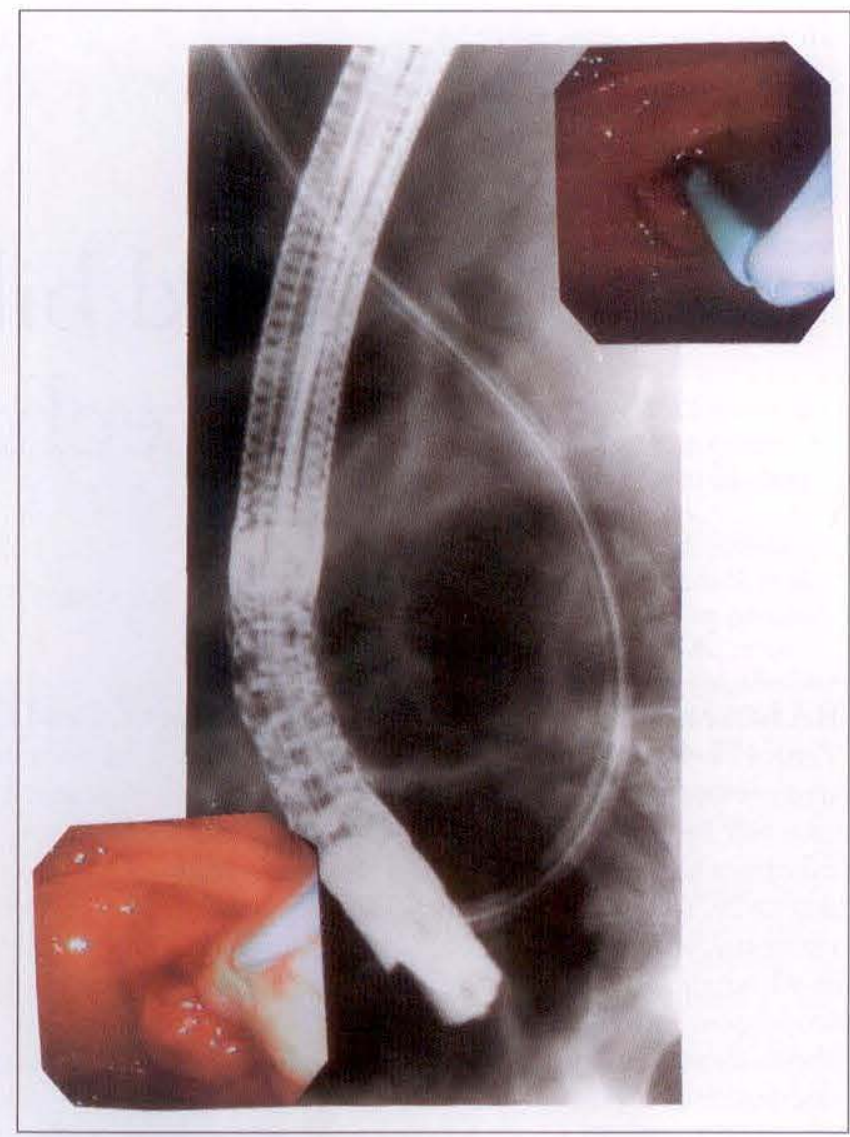

Figure 2) 14 French endoprosthesis in patient with malignant obstructive jaundice and cholangitis (inserts)
Caveats for conventional biliary stent placement include the following. First, assure adequate guidewire placement above the stenosis. Biliary manipulation over an inadequate length of wire is associated with inadvertent displacement or inadequate vector forces. Second, don't try to place a large calibre endoprosthesis through an extremely tight stenosis without initial dilation. The latter most commonly uses dilating catheters for malignant stenoses and hydrostatic balloons for benign strictures. When using the latter, use dilute contrast solution and radiographic control to assure waist dilation of the balloon. Note that there are no data to suggest that 3 mins of balloon inflation are any more successful than $15 \mathrm{~s}$. Because these dilations invariably induce severe biliary colic and arouse a previously narcotized and cooperative patient into an agitated state, I tend to limit inflation duration. Third, use a stiffening catheter to maximize the ease of endoprosthesis insertion. Fourth, se- lect a stent contingent upon the clinical situation. Most commonly this means not only measurement to assure appropriate length accounting for the 25 to $33 \%$ magnification factor noted with most $\mathrm{x}$-ray units, but also appropriate diameter. In malignant disease this is most commonly a 10 to 11.5 French diameter stent. However, when such a prosthesis is used for hilar lesions, an entire liver lobe is occasionally occluded and may require downsizing of the prosthesis diameter. Moreover, in both benign biliary strictures and type III cholangiocarcinoma stenoses, some endoscopists claim superior results using at least two endoprostheses.

On the other hand, there are settings (like postoperative cystic duct stump leaks) which not only do not require sphincterotomy in most instances, but also close readily with small diameter stents ( 7 to 8.5 French) placed across an intact papilla.

Stent placement usually is facili- tated by endoscope position along the lesser curvature of the stomach, an en face papilla and an endoscope tip 1 to 2 $\mathrm{cm}$ from the papilla. Most of the work associated with stent placement is done with the elevator in concert with a taut guidewire, overtube and pusher tube. To be avoided are long distances from the papilla where the endoprosthesis may take a downward bow. In this setting, the endoprosthesis vector force is no longer along the bile duct axis. This is a frequent cause of procedure failure. Difficulty passing the stent through the stenosis proper can be minimized in three ways. To begin with, do a sphincterotomy. This may change the angle of stent insertion and minimizes friction at the papilla. Next, simultaneously insert your pushing catheter and extend your endoscope tip to the papilla until 'red-out'. This is the most frequently successful technique I use. Finally, if all else fails, ascertain that the stent is parallel to the bile duct axis and that the scope is high along the lesser curve. 


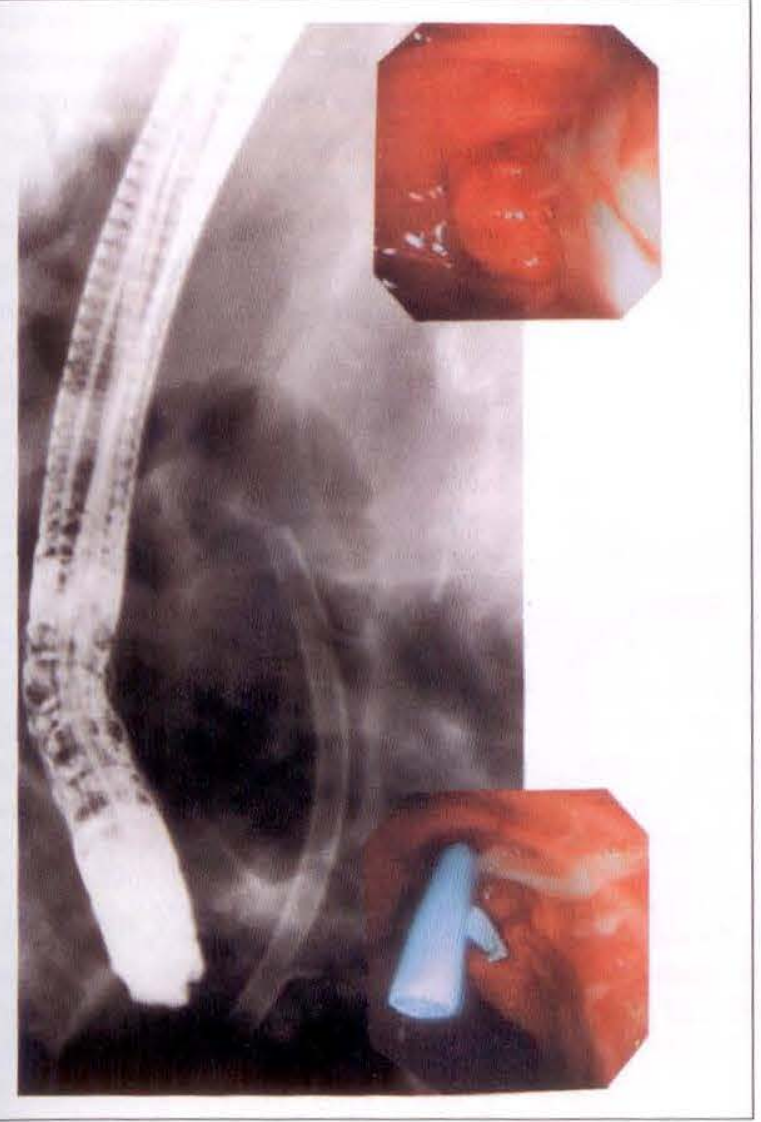

Figure 3) Proper stent placement in patient depicted in Figure 2. Stent placed through prototype duodenoscope with $5.5 \mathrm{~mm}$ biopsy channel

Simultaneously using the pusher catheter to fix the stent, sharply pull or jerk the scope higher along the lesser curvature of the stomach. Although the latter move has some risk of Mallory Weiss tear of the esophogastric junction or concomitant guidewire displacement, it will often succeed in pushing an endoprosthesis through a tight stricture when all else has failed.

Adequate endoprosthesis placement requires immediate assessment of your treatment. Is there adequate biliary decompression? Is one ductal system or the cystic duct completely occluded? Is there too much stent left in the duodenum with the attendant risk of contralateral duodenal wall ulcer or perforation?

\section{RESULTS}

Results of conventional biliary prosthesis placement are obviously contingent upon endoscopist experience, the support system, accessory equipment available and the reason for which the procedure is undertaken.

\section{MALIGNANT OBSTRUCTIVE JAUNDICE}

There have been at least nine nonrandomized trials using endoscopically placed endoprostheses in malignant obstructive jaundice (9) (Table 1). Successfully placed in 778 of 856 attempts (91\%), $20 \%$ of patients developed acute complications, and 30-day mortality ranged from 3 to $20 \%$ (mean $12 \%)$. In these nine trials, median time to stent occlusion approximated four to six months and survival approximated 4.9 months (range 2.8 to 6.8 ).

Additionally, there have been three separate studies in which patients with malignant obstructive jaundice have been randomized to endoscopic or surgical palliation (9) (Table 2). None of these studies has demonstrated survival advantage for either modality (median survival: surgery, 112 days; endoscopy, 130 days). Moreover, successful palliation (91\% surgery, 93\% endoscopy), 30 -day mortality (17\% surgery, $12 \%$ endoscopy) and procedure-related complications ( $42 \%$ surgery, $30 \%$ en- doscopy) were all comparable in these prospective studies. In contrast, our institution has previously published data demonstrating that while survival figures were comparable between patients treated with surgery or endoprostheses (nine to 10 months), patients treated with the latter modality had statistically significant shorter hospitalization time and lower total cost of medical care to death (approximately twothirds of surgical costs) (22).

The problem with endoprosthesis placement as palliation for malignant obstructive jaundice is not the potential of missing the occasional patient who is resectable for cure. Rather, it relates to stent occlusion secondary to bacterial biofilm development, resultant recurrent jaundice with or without cholangitis and need for prosthesis exchange (23-26). As such, many of these patients are tethered to their endoscopist who in turn, are tethered to their stented patients. Despite changes in stent design (revision from pigtail to straight/Amsterdam type), diameter 


\section{TABLE 1}

\section{Endoscopic stent insertion in malignant obstructive jaundice*}

Median age in years
Attempted/successful placement
Acute complications (\%)
Procedure-related mortality (\%)
30-day mortality (\%)
Median time to stent occlusion (months)
Median survival (months)

-Nine nonrandomized studies: adapted from reference 9

TABLE 2

Randomized, prospective trials endoscopic stent versus surgical bypass*

\begin{tabular}{lcc}
\hline & \multicolumn{1}{c}{ Stent } & Surgery \\
\hline Attempted/successful stent placement & 109 of $117(93 \%)$ & 102 of $112(91 \%)$ \\
Procedure-related complications $(\%)$ & $30(23$ to 36$)$ & $42(20$ to 56$)$ \\
30 -day mortality (\%) & $12(6$ to 20$)$ & $17(5$ to 32$)$ \\
Median survival (days) & $130(84$ to 152$)$ & $112(100$ to 125$)$ \\
\hline
\end{tabular}

"Combined data, references 6-8

(initially 7 French, now 10 to 11.5 French) (25), and methods to ensure endoprosthesis patency (various antibiotics, ursodiol to enhance bile flow and antimucin drugs to prevent initial bacterial adherence) (27) occlusions remain problematic and require urgent intervention.

\section{BENIGN BILIARY STRICTURES}

Postoperative stenoses: Geenen et al (12) treated 25 patients with postoperative stenoses with balloon dilation (23) and/or endoprostheses placement (18) for up to two years (12). Assessing such parameters as radiological stricture diameter, drainage time and degree of biliary dilation, as well as clinical symptoms and liver function test abnormalities, 18 of the patients were felt to have a good result at mean follow-up of four years and all were asymptomatic for at least two years. Ponchon and colleagues (13) treated 24 patients with spontaneous or postoperative biliary fistulas, the majority of whom also had biliary stenoses. Two-thirds of the patients had rapid fistula resolution following sphincterotomy with or without concomitant balloon dilation of the stricture and endoprosthesis insertion.

Berkelhammer et al (14) successfully inserted stents in $86 \%$ of 29 patients with 32 postoperative strictures. Five of these patients had concomitant biliary fistulas (14). Of the 23 patients followed for a mean of 19 months postprosthesis removal, $48 \%$ had an excellent result, and an additional $26 \%$ had a good clinical result. Finally, Davids et al (15) were successful in placing two endoprostheses in 66 of 70 patients with postoperative stenosis of the bile duct. Exchanged bimonthly for one year, stents were retrieved and mean follow-up was 42 months. Six patients required an operation in the first year. Good or excellent clinical results were noted in $83 \%$ of patients long term. Seventeen per cent of the patients restrictured after endoprosthesis removal.

\section{SCLEROSING CHOLANGITIS}

The endoscopic approach to sclerosing cholangitis was originally reported in 1983 (20). Since then, a variety of therapeutic techniques have been reported in individual patients or small series, and include sphincterotomy alone, sphincterotomy plus balloon dilation with or without stent placement, and nasobiliary drain placement with saline, methyl tert-butyl ether, EDTA, antibiotic or steroid lavage. In a retrospective survey of 3000 American Society for Gastrointestinal Endoscopy members compiled in 1985, there were 46 cases of postcholecystectomy stricture and 15 cases of sclerosing cholangitis stricture treated with balloon dilation (28). A technical success rate approximating $75 \%$ was followed by radiographic and symptomatic improvement in twothirds to three-quarters of the patients. Johnson et al (16), in turn, undertook endoscopic sphincterotomy and gravel removal in 10 sclerosing cholangitis patients, eight of whom had balloon dilation of a dominant stenosis and three of whom had endoprosthesis insertion. Serum bilirubin, alkaline phosphatase and transaminases fell significantly as did episodes of cholangitis requiring hospitalization. In a recent update of their series (17), these authors demonstrated significant improvement in hospitalization, radiography and laboratory parameters in 35 sclerosing cholangitis patients treated endoscopically and followed for a mean of two years.

\section{CHRONIC PANCREATITIS}

Occurring in 10 to $27 \%$ of patients with chronic pancreatitis, distal bile duct strictures are usually asymptomatic (18). They can, however, be associated with cholestasis, cholangitis, liver abscesses and secondary biliary cirrhosis. There have been several small series published using endoprostheses for the biliary complications of chronic pancreatitis, but long term follow-up has been lacking. In the largest series to date, Devière et al (18) stented 25 chronic pancreatitis patients, 19 of whom were jaundiced, seven of whom had cholangitis, including three with liver abscesses (18). Although technically successful in all patients, only three were asymptomatic without stent placement at a mean follow-up of 14 months (18). With the exception of two early deaths and four patients lost to follow-up, all other patients ultimately required surgical intervention for the biliary blockage. The authors concluded that while endoscopic biliary drainage was effective in the acute treatment of jaundice or cholangitis, long term resolution of the stricture rarely occurred. Waxman and Huibregtse (19) followed 26 patients stented for cholestasis and biliary stricture as a consequence of chronic pancreatitis. Of the eight patients who developed stent occlusion, three developed cholangitis, 
one of whom died in septic shock. Only six patients $(23 \%)$ remained well after stent retrieval and 15 required chronic stent exchange. As did Devière et al, Waxman and Huibregtse recommended that stent placement in chronic pancreatitis be reserved for the symptomatic patient at high surgical risk.

\section{REFERENCES}

1. Bornman P, Harries-Jones EP, Tobias $\mathrm{R}$, et al. Prospective controlled trial of transhepatic biliary endoprosthesis versus bypass surgery for incurable carcinoma of head of pancreas. Lancet 1986;i:69-71.

2. Huibregtse K, Katon RG, Coene PP, Tytgat GNJ. Endoscopic palliative treatment in pancreatic cancer. Gastrointest Endosc 1986;32:334-8.

3. Siegel JH, Snady H. The significance of endoscopically placed prostheses in the management of biliary obstruction due to carcinoma of the pancreas: Results of nonoperative decompression in 277 patients. Am J Gastroenterol 1986;81:634-41.

4. Waltar DC, Fausel CS, Brant B. Endoscopic biliary stents and obstructive jaundice. Am J Surg 1987;153:444-7.

5. Speer AG, Cotton PB, Russel RCG, et al. Randomized trial of endoscopic versus percutaneous stent insertion in malignant obstructive jaundice. Lancet 1987;ii:57-62.

6. Shepherd HA, Royle G, Ross APR, et al. Endoscopic biliary endoprosthesis in the palliation of malignant obstruction of the distal common bile duct: A randomized trial. $\mathrm{Br}$ J Surg 1988;75:1166-8.

7. Anderson JR, Sorensen SM, Kruse A, et al. Randomized trial of endoscopic endoprosthesis versus operative bypass in malignant obstructive jaundice. Gut 1989;30:1132-5.

8. Dowsett JF, Russell RCG, Hatfield ARW, et al. Malignant obstructive jaundice: A prospective randomized trial of by-pass surgery versus endoscopic stenting. Gastroenterology 1989;96:A128.

9. Naggar E, Krag E, Matzen P. Endoscopically inserted biliary endoprosthesis in malignant

\section{CONCLUSIONS}

Standard endoprosthesis placement has evolved from a palliative manoeuvre in the treatment of malignant obstructive jaundice to palliative or definitive therapy for a variety of benign biliary diseases. Stent occlusion with obstructive jaundice or cholangitis re-

obstructive jaundice. A survey of the literature. Liver 1990;10:321-4.

10. Siegel JH. Combined endoscopic dilatation and insertion of large diameter endoprosthesis for bile duct obstruction. Gastrointest Endosc 1984;30:91-2.

11. Huibregtse K, Katon RM, Tytgat GN. Endoscopic treatment of postoperative biliary strictures. Endoscopy 1986;18:133-7.

12. Geenen DJ, Geenen JE, Hogan WJ, et al. Endoscopic therapy for benign bile duct strictures. Gastrointest Endosc 1989;35:367-71.

13. Ponchon T, Gallez J-F, Vallette P-J, et al. Endoscopic treatment of biliary tract fistulas. Gastrointest Endosc 1989;35:490-8.

14. Berkelhammer C, Kortan P, Haber GB. Endoscopic biliary prostheses as treatment for benign postoperative strictures. Gastrointest Endosc 1989;35:95-101.

15. Davids PHP, Rauws EAJ, Coene PPLO, et al. Endoscopic stenting for post-operative biliary strictures. Gastrointest Endosc 1992;38:12-8.

16. Johnson GK, Geenen JE, Venu RP, Hogan WJ. Endoscopic treatment of biliary duct strictures in sclerosing cholangitis: Follow-up assessment of a new therapeutic approach. Gastrointest Endosc 1987;33:9-12.

17. Johnson GK, Geenen JE, Venu RP, et al. Endoscopic treatment of biliary tract strictures in sclerosing cholangitis: A larger series and recommendations for treatment. Gastrointest Endosc 1991;37:38-43.

18. Devière J, Devaere $S$, Baize $M$, Cremer M. Endoscopic biliary drainage in chronic pancreatitis. Gastrointest Endosc 1990;36:96-100.

19. Waxman I, Huibregtse K. Endoscopic therapy for chronic pancreatitis. Gut 1993. (In press) mains a major obstacle to prolonged stent placement when conventional prostheses are used. Neither material changes nor pharmaceutical agents (ursodeoxycholic acid, antibiotics, acetylsalicylic acid) have been definitively shown to prevent bacterial biofilm and subsequent stent occlusion in vivo.

20. Siegel JH, Guelrud M. Endoscopic cholangiopancreatoplasty: Hydrostatic balloon dilation in the bile duct and pancreas. Gastrointest Endosc 1984;29:99-103.

21. Rustgi AK, Schapiro RH. Biliary stents for common bile duct stones. Gastrointest Endosc Clin North Am 1991;1:79-92.

22. Brandabur JJ, Kozarek RA, Ball TJ, et al. Nonoperative versus operative treatment of obstructive jaundice in pancreatic cancer: Cost and survival analysis. Am J Gastroenterol 1988;83:1132-9.

23. Speer AG, Cotton PB, Rode J, et al. Biliary stent blockage with bacterial biofilm. A light and electron microscopy study. Ann Intern Med 1988;108:546-53.

24. Motte S, Devière J, Dumonceau J-M, et al, Risk factors for septicemia following endoscopic biliary stenting. Gastroenterology 1991;101:1374-81.

25. Speer AG, Cotton PB, MacRae KD. Endoscopic management of malignant biliary obstruction: Stents of 10 French gauge are preferable to stents of 8 French gauge. Gastrointest Endosc 1988;34:412-7.

26. Matsuda Y, Shimakura K, Akamatsa T. Factors affecting the patency of stents in malignant biliary obstructive disease: Univariate and multivariate analysis. Am J Gastroenterol 1991;86:843-9.

27. Smith JM, Out MMJ, Groen AK, et al. A placebo-controlled study on the efficacy of aspirin and doxycycline in preventing clogging of biliary endoprostheses. Gastrointest Endosc 1989;35:485-9.

28. Kozarek RA. Hydrostatic dilation of gastrointestinal stenoses: A national survey. Gastrointest Endosc 1986;32:15-9. 


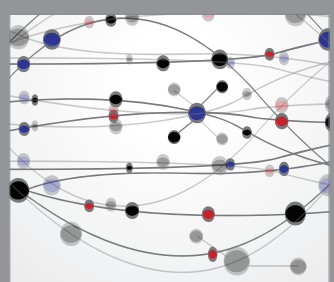

The Scientific World Journal
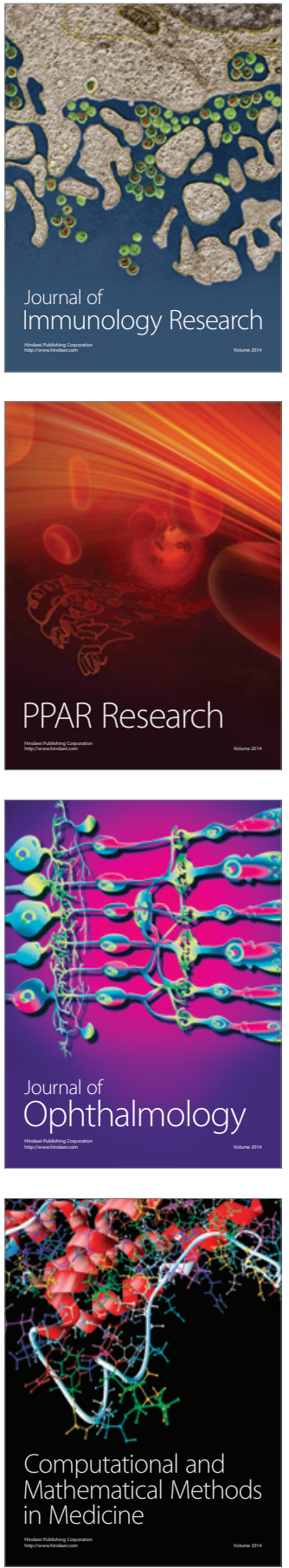

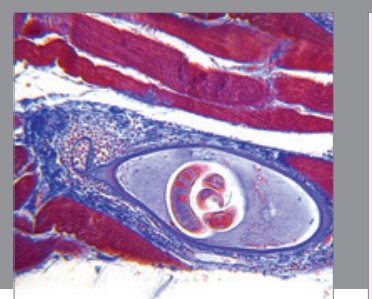

Gastroenterology Research and Practice

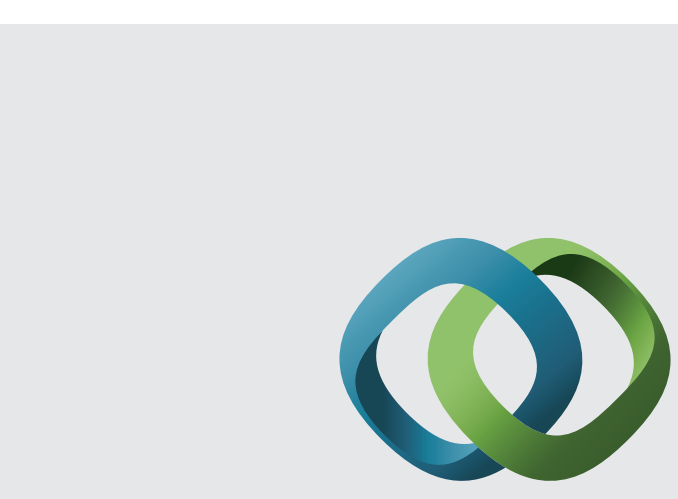

\section{Hindawi}

Submit your manuscripts at

http://www.hindawi.com
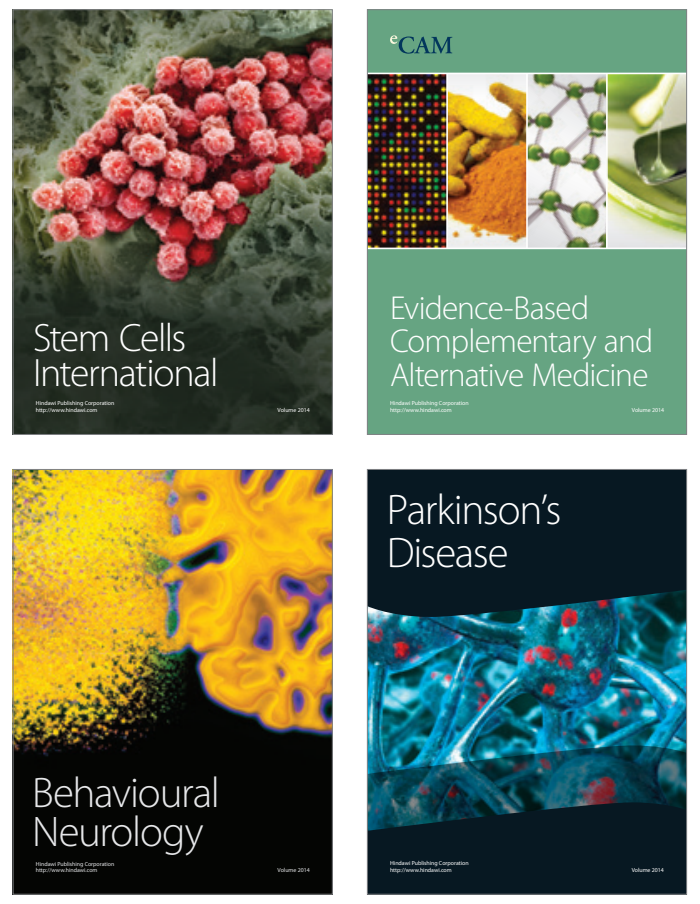
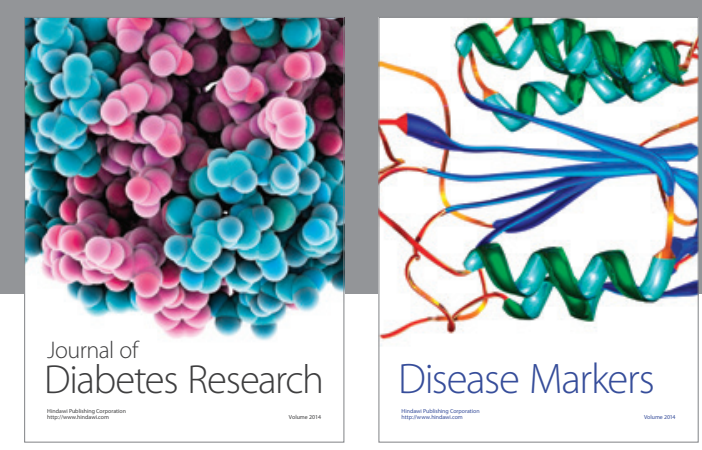

Disease Markers
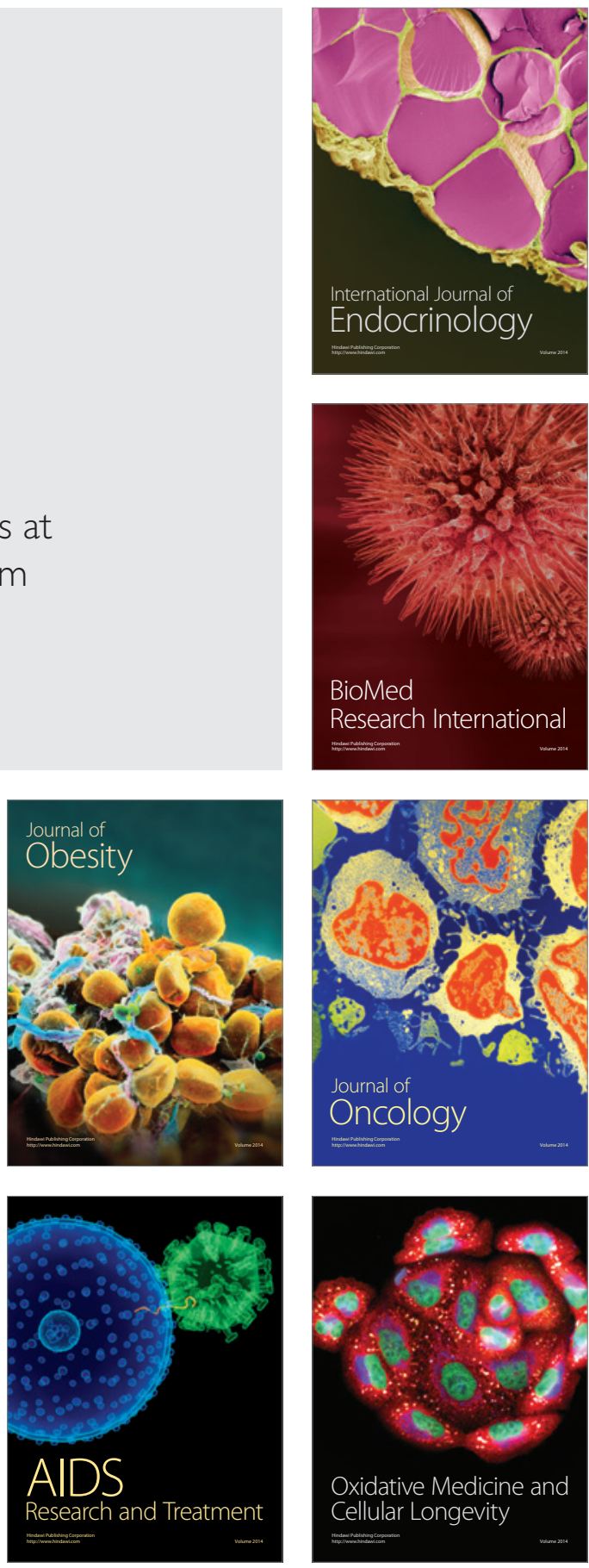